\title{
Blue-wavelength Light Therapy for Post-traumatic Brain Injury Sleepiness, Sleep Disturbance, Depression, Fatigue: A Systematic Review and Network Meta-analysis
}

\section{Karan Srisurapanont}

Faculty of Medicine, Chiang Mai University, Chiang Mai, Thailand

Yanisa Samakarn

Faculty of Medicine, Chiang Mai University, Chiang Mai, Thailand

\section{Boonyasit Kamklong}

Faculty of Medicine, Chiang Mai University, Chiang Mai, Thailand

Phichayakan Siratrairat

Faculty of Medicine, Chiang Mai University, Chiang Mai, Thailand

Arina Bumiputra

Faculty of Medicine, Chiang Mai University, Chiang Mai, Thailand

Montita Jaikwang

Faculty of Medicine, Chiang Mai University, Chiang Mai, Thailand

Manit Srisurapanont ( $\nabla$ manit.s@cmu.ac.th )

Department of Psychiatry, Faculty of Medicine, Chiang Mai University, Chiang Mai, Thailand https://orcid.org/0000-0001-6203-1206

\section{Research}

Keywords: light therapy, traumatic brain injury, sleepiness, sleep disturbance, depression, fatigue

Posted Date: August 13th, 2020

DOI: https://doi.org/10.21203/rs.3.rs-58112/v1

License: (c) (i) This work is licensed under a Creative Commons Attribution 4.0 International License. Read Full License 


\section{Abstract}

Background: We aimed to determine the efficacy of blue-wavelength light therapy (BWLT) for posttraumatic brain injury (TBI) sleepiness, sleep disturbance, depression, and fatigue.

Methods: We searched six databases for randomized controlled trials of BWLT for adults with a history of TBI. Outcomes of interest included sleepiness, sleep disturbance, depression, or fatigue. We conducted random-effect frequentist network meta-analyses (NMA) to compare the efficacy and a pairwise metaanalysis to examine the dropout rates.

Results: We included four randomized controlled trials that compared BWLT, amber light therapy, and no light therapy. BWLT was significantly superior in reducing depression as compared to amber light therapy $(\mathrm{SMD}=0.57,95 \% \mathrm{Cl}=0.04$ to 1.10$)$ and no light therapy $(\mathrm{SMD}=0.81,95 \% \mathrm{Cl}=0.20$ to 1.43$)$. BWLT was also significantly superior in reducing fatigue as compared to amber light therapy $(S M D=1.00,95 \% \mathrm{Cl}=$ 0.14 to 1.86$)$ and no light therapy $(S M D=1.09,95 \% \mathrm{Cl}=0.41$ to 1.76$)$. There was no significant heterogeneity of depression and fatigue data $\left(\mathrm{I}^{2}=0 \%\right.$ for both). The relative risk of dropout rates $(95 \% \mathrm{Cl})$ shows no significant difference between BWLT and amber light therapy groups $(\mathrm{RR}=3.72,95 \% \mathrm{Cl}=0.66$ to $\left.21.34,1^{2}=0 \%\right)$.

Conclusion: BWLT may be effective for post-TBI depression and fatigue. Due to the risks of bias and the inability to exclude publication bias among included studies, the current evidence remains insufficient to support the clinical application of BWLT for post-TBI depression and fatigue.

Protocol registration: The protocol of this systematic review is available at Open Science Framework (https://osf.io/yf2qe/).

\section{Introduction}

Traumatic brain injury (TBI) is common, increasingly prevalent, and one of the leading causes of disability worldwide. In 2016, there were 27 -million new cases of TBI with an age-standardized incidence rate of 369 per 100000 population [1]. These figures reflect an increased incidence of $8.4 \%$ from 1990 to 2016 and have resulted in 8 million years of life with a disability. As a medical condition related to road traffic injuries, TBI is more prevalent in low- and middle-income countries, especially in Africa and Southeast Asia [2].

Long-term behavioral sequelae of TBI play an crucial role in causing disability. Although the pathophysiology of post-TBI behavioral symptoms is complex and not fully understood, several studies have reported that (excessive daytime) sleepiness, sleep disturbance, depression, and fatigue are common in patients with a TBI. One to two years post-TBI, $43 \%-67 \%$ of the patients still have these behavioral symptoms [3-5]. Post-TBI sleepiness, sleep disturbance, depression, and fatigue seriously undermine patient rehabilitation, recovery, community reintegration, well-being, and quality of life [6-8]. 
Post-TBI depression, fatigue, and sleepiness appear to be a symptom cluster similar to winter depression syndrome. In patients with major depressive disorder, fatigue is correlated with sleepiness and depression severity [9]. These three symptoms are similar to the core features of winter depression, including depression, low energy, and hypersomnia [10]. The evidence to date supports the use of bright light therapy as a treatment of choice for winter depression - a type of seasonal affective disorder [11]. It is, therefore, of interest to evaluate the efficacy of bright light therapy for post-TBI depression, fatigue, and sleepiness

The exposure to blue- (or short-) wavelengths of light can affect subjective feelings of alertness and circadian physiology. Bright light therapy has physiological effects by resynchronizing the biological clock (circadian system), enhancing alertness, increasing sleep pressure (homeostatic system), and acting on serotonin, and other monoaminergic pathways [12]. Morning exposure to bright light therapy can suppress nocturnal melatonin secretion from the pineal body resulting in the reduction of excessive daytime sleepiness and insomnia at night, as well as improving alertness [12-14]. Blue and red light are at the opposite ends of the visible spectrum. They characteristically have short wavelengths with high energy and long wavelengths with low energy, respectively. With a higher level of energy, blue-wavelength light would imply a natural preference to other wavelengths of light for the treatment of depression, fatigue, sleepiness, and sleep disturbance. In addition, previous studies have shown that non-visual behavioral responses are highly sensitive to short-wavelength light $[15,16]$.

Because bright light can be used to phase shift circadian rhythms, a number of electronic devices have been developed and designed for treating medical conditions related to circadian rhythm disturbance. Of many devices, light boxes are an electronic device commonly used for light therapy. Although light boxes can be used for treating circadian rhythm sleep disorders, they are not considered as medical devices and not regulated by an agency responsible for food and drug administration. However, a light box should be clinical efficacy, ocular and dermatologic safety, and visual comfort [17].

More interventions are needed for the treatment of post-TBI sleepiness, sleep disturbance, depression, and fatigue. Only stimulants and strategic use of caffeine/nap are possible treatment options for postTBI sleepiness [18]. Although there is some evidence to support the benefits of antidepressants and/or cognitive-behavioral therapy for post-TBI depression, there is no well-established treatment for this particular depression [19]. A recent systematic review found little evidence to support the efficacy of aquatic physical activity, mindfulness-based stress reduction, and computerized working-memory training for fatigue [20]. However, this review did find a small-sample randomized controlled trial (RCT) reporting the benefits of BWLT for post-TBI fatigue [21].

Based on the rationales above and the need for more treatment options to manage these behavioral symptoms, we proposed to conduct a systematic review to determine the efficacy of and adherence to BWLT for post-TBI sleepiness, sleep disturbance, depression, and fatigue.

\section{Methods}


The protocol of this systematic review was prospectively registered at Open Science Framework (https://osf.io/yf2qe/). At first, we planned to conduct a pairwise meta-analysis. However, we found some difficulties in analyzing the dataset comparing BWLT with two control interventions and a trial with three studied groups. Because a network meta-analysis (NMA) is more suitable for this kind of dataset, we decided to conduct a NMA to aggregate these data. The report of this review followed the PRISMA 2015 Network Meta-Analysis Checklist [22]. For all review tasks independently conducted by two reviewers, any discrepancy was resolved using a consensus discussion with a third-party reviewer.

\section{Eligible criteria}

The eligibility criteria for an included trial were as follows: i) a randomized controlled trial; ii) adult participants (> 18 years old) with a history of TBl; iii) an experimental intervention of BWLT; iv) a control intervention of any kind of light therapy, e.g., amber light therapy, as well as no light therapy; and v) an outcome of sleepiness, sleep disturbance, depression, or fatigue.

\section{Information sources, searches, and study selection}

We performed database searches for eligible trials in Pubmed, Scopus, Web of Science, Cochrane Library, Academic Search Complete, and CINAHL Complete. Key search terms included (light OR phototherapy) AND (((head OR brain) AND (trauma* OR injur*)) OR concussion) AND random*. The supplementary file of this article provides the details of our database searches (see Appendix 1 in Supplementary file). We searched each database from its inception. All retrieved items were imported into the Zotero program for the removal of duplicates. Non-duplicate records were then imported into the Rayyan QCRI website for the selection of trials.

Neither language restriction nor publication date limitation was applied. Two reviewers (KS and YS) independently screened the titles and abstracts, evaluated the full-text publications, and assessed the trial quality.

\section{Data collection process and data extraction}

Two reviewers (KS and PS) independently extracted the trial data using a data record form. Characteristics of interest for each study included: i) study ID (first author, year); ii) participant characteristics, including age, inclusion criteria, gender, diagnostic procedure(s), and details of the traumatic brain injury (e.g., Glasgow Coma Score); iii) details of light therapy and control intervention, including wavelength; iv) management guidelines and additional intervention(s); v) per-protocol analysis of the outcomes; and vi) the measures used for outcome assessment.

\section{Data items}

The primary outcome of efficacy was sleepiness. The secondary outcomes included sleep disturbance, depression, and fatigue. For each outcome, we focused on the mean change scores and the SDs. The change scores were preferred because they could remove the between-person variability from the 
analysis, which results in greater efficient and more statistical power for detecting the differences [23]. Dropout rates were the measure of adherence to treatment. These data, as well as the number of participants for analyses, were extracted from the published articles.

For a missing standard deviation, we applied a sequence of strategies as follows: i) using the calculator of RevMan 5.4; ii) assuming that the standard deviations of all comparison groups were equal and using the mean and effect size for calculation; iii) contacting the corresponding author of that particular study; iv) using the endpoint standard deviation of the particular group and outcome; and iv) measuring the graphs using the Engauge Digitizer version 6.0 software.

The extracted outcomes were used for computing the standardized mean differences (SMDs) and relative risks (RRs), as well as $95 \%$ confidence intervals (Cls).

\section{Geometry of the network}

We compared the SMDs and RRs between interventions directly and indirectly. In the networks, an intervention was drawn by a node, and a comparison between the interventions was shown by an edge. The node sizes and the edge thickness indicate the number of studies and comparisons, respectively.

\section{Risk of bias within individual trials}

Two reviewers (KS and YS) independently assessed the quality of included trials using the RoB 2 - a revised Cochrane risk-of-bias tool for randomized trials [24]. The bias tool evaluated five aspects of the trial as follows: i) randomization process; ii) adherence to the assigned intervention(s); iii) missing outcome data; iv) the bias of measurement, and v) the bias of the reported results. The levels of bias obtained from these aspects were used to determine the overall bias of each study.

\section{Summary measures and methods of analysis}

For each pairwise comparison, we used the SMDs following weight reduction as a measure of efficacy. The positive SMDs indicate the superiority of BWLT against amber light therapy or no light therapy. We conducted random-effect pairwise meta-analyses and frequentist network meta-analyses (NMA) on an intention-to-treat analysis. We described the ranking and uncertainty of each intervention using the league table for assessing the strength of evidence obtained from the NMAs.

\section{Assessment of heterogeneity and inconsistency}

For each outcome, heterogeneity was visualized with forest plots and quantified using ${ }^{2}$ statistics [25]. A $P^{2}$ value of $75-100 \%$ was rated as substantial heterogeneity. We used both general and local approaches to determine between-design and within-design inconsistency, respectively. In addition, we also calculated the inconsistency between direct and indirect evidence of each comparison.

\section{Risks of bias across studies}

We assessed the risks of bias across studies using the funnel plots to explore the publication bias [23]. 


\section{Additional analysis}

For the outcome in which all studies compared the same pair of interventions, we conducted a pairwise meta-analysis on an intention-to-treatment analysis using a random-effect model.

\section{Statistical software}

The NMAs were carried out using the netmeta version 1.2-1 package [26]. The risk of bias was visualized using the robvis version 0.3.0 package [27]. The meta-analysis was performed using the meta version 4.12-0 package [28]. All packages were used under the $\mathrm{R}$ Program version 3.6 via the Rstudio software version $1.2 .5[29,30]$.

\section{Results}

\section{Study selection}

The database searches on July 4, 2020 retrieved 1,697 items (see Fig. 1 and Appendix 1 in Supplementary file). After the duplicate removal, 1,034 records remained for title and abstract screening. We assessed 19 full-text publications and, finally, included four randomized controlled trials in this systematic review [21, 31-33].

\section{Network structure and geometry}

Figure 2 shows the network graphs comparing BWLT ( 4 trials, $n=53$ ), amber light therapy ( 3 trials, $n=42$ ), and no light therapy ( 2 trials, $n=20$ ) for sleepiness, sleep disturbance, depression, and fatigue. The comparisons included BWLT vs. amber light therapy (3 trials), BWLT vs. no light therapy (2 trials), and amber light therapy vs. no light therapy (2 trials). While a three-arm trial compared BWLT, amber light therapy, and no light therapy, others were the comparisons of BWLT and amber/no light therapy. Three networks including in the NMAs were as follows: i) sleepiness ( 3 treatments among 6 pairwise comparisons in 4 RCTs) (see Fig. 2A); ii) sleep disturbance and depression (3 treatments among 5 pairwise comparisons in 3 RCTs) (see Fig. 2B; and iii) fatigue (3 treatments among 4 pairwise comparisons in 2 RCTs) (see Fig. 2C).

\section{Study characteristics}

This systematic review included four randomized controlled trials participated by 117 patients with a history of TBI (see Table 1). The studies were conducted in patients with mild TBI (2 RCTs), severe TBI (1 RCT), and mixed severity of TBI (1 RCT). Brain injury had occurred between 6.75 months and nine years prior to the study enrolment. Except Sinclair' study, which was a three-arm trial, the other three studies were two-arm trials. The wavelengths of blue light therapy and amber light therapy used ranged between $\lambda_{\max }=465 \mathrm{~nm}$ and $\lambda_{\max }=480 \mathrm{~nm}$ and ranged between $\lambda_{\max }=530 \mathrm{~nm}$ and $\lambda_{\max }=578 \mathrm{~nm}$. While three trials provided light therapy using a LED light box [21,31,33], one trial gave light therapy using a face- 
mounted device resembling glasses [32]. All instances of light therapy were self-administered at home in the morning. 
Table 1

Characteristics of four studies included in the systematic review.

\begin{tabular}{|c|c|c|c|}
\hline $\begin{array}{l}\text { Study } \\
\text { (country, } \\
\text { study } \\
\text { duration) }\end{array}$ & Characteristics of the participants & Interventions ( $\mathrm{n}$ ) & Outcomes \\
\hline \multirow[t]{5}{*}{$\begin{array}{l}\text { Sinclair } 2014 \\
\text { (Australia, } 4 \\
\text { weeks) }\end{array}$} & $\begin{array}{l}\text { - Patients with a history of mixed severity } \\
\text { of TBI, who had significant fatigue or } \\
\text { sleep problems }\end{array}$ & \multirow{5}{*}{$\begin{array}{l}\text { 1. } \operatorname{BWLT}\left(\lambda_{\max }=\right. \\
465 \mathrm{~nm})(\mathrm{n}=10) \\
\text { 2. } \operatorname{ALT}\left(\lambda_{\max }=574 \mathrm{~nm}\right) \\
(\mathrm{n}=10) \\
\text { 3. NLT }(\mathrm{n}=10) \\
\text { (For intervention } 1 \text { and } \\
\text { 2: } 45 \text { minutes daily in } \\
\text { the morning) }\end{array}$} & $\begin{array}{l}\text { Sleepiness: } \\
\text { ESS }\end{array}$ \\
\hline & - \% Male: 83.3 & & $\begin{array}{l}\text { Sleep } \\
\text { quality: } \\
\text { PSQI }\end{array}$ \\
\hline & - Mean age: 42.0 years & & Dep \\
\hline & & & BDI-II \\
\hline & - Mean duration after TBI: 36.9 months & & $\begin{array}{l}\text { Fatigue: } \\
\text { FSS }\end{array}$ \\
\hline \multirow[t]{5}{*}{$\begin{array}{l}\text { Quera Salva } \\
2019 \text { (France, } \\
4 \text { weeks) }\end{array}$} & $\begin{array}{l}\text { - Patients with a history of severe TBI, } \\
\text { who had significant sleepiness, sleep } \\
\text { disturbance, or fatigue }\end{array}$ & \multirow{4}{*}{$\begin{array}{l}\text { 1. BWLT }\left(\lambda_{\max }=\right. \\
468 \mathrm{~nm})(\mathrm{n}=10) \\
-30 \text { minutes daily after } \\
\text { waking } \\
\text { 2. NLT }(n=10)\end{array}$} & $\begin{array}{l}\text { Sleepiness: } \\
\text { ESS }\end{array}$ \\
\hline & - \% Male: 55 & & $\begin{array}{l}\text { Sleep } \\
\text { quality: } \\
\text { PSQI }\end{array}$ \\
\hline & - Mean age: 36.6 years & & \\
\hline & - Initial GCS: 5.94 & & HRSD-17 \\
\hline & - Mean duration after TBI: 9.03 years & & $\begin{array}{l}\text { Fatigue: } \\
\text { FSS }\end{array}$ \\
\hline \multirow{5}{*}{$\begin{array}{l}\text { Killgore } 2020 \\
\text { (USA, } 6 \\
\text { weeks) }\end{array}$} & $\begin{array}{l}\text { - Patients with a history of mild TBI, who } \\
\text { had sleep-related problems }\end{array}$ & $\begin{array}{l}\text { 1. BWLT }\left(\lambda_{\max }=\right. \\
469 \mathrm{~nm})(\mathrm{n}=18)\end{array}$ & \multirow[t]{5}{*}{$\begin{array}{l}\text { Sleepiness: } \\
\text { ESS }\end{array}$} \\
\hline & - \% Male: 50 & 2. $A L T\left(\lambda_{\max }=578 \mathrm{~nm}\right)$ & \\
\hline & - Mean age: 23.7 years & $(\mathrm{n}=$ & \\
\hline & - Initial GCS: N/A & \multirow{2}{*}{$\begin{array}{l}\text { (For both interventions: } \\
30 \text { minutes daily in the } \\
\text { morning) }\end{array}$} & \\
\hline & - Mean duration after TBI: 6.75 months & & \\
\hline
\end{tabular}

ALT: Amber Light Therapy; NLT: No Light Therapy; BWLT: Blue-Wavelength Light Therapy.

TBI: Traumatic brain injury; GCS: Glasgow Coma Scale; BDI-II: Beck Depression Inventory, 2nd edition; HRSD-17: 17-item Hamilton Rating Scale for Depression; FSS: Fatigue Severity Scale; ESS: Epworth Sleepiness Scale; PSQI: Pittsburgh Sleep Quality Index 


\begin{tabular}{|c|c|c|c|}
\hline $\begin{array}{l}\text { Study } \\
\text { (country, } \\
\text { study } \\
\text { duration) }\end{array}$ & Characteristics of the participants & Interventions ( $\mathrm{n}$ ) & Outcomes \\
\hline \multirow{5}{*}{$\begin{array}{l}\text { Raikes } 2020 \\
\text { (USA, } 6 \\
\text { weeks) }\end{array}$} & $\begin{array}{l}\text { - Patients with a history of mild TBI, who } \\
\text { had disrupted sleep }\end{array}$ & $\begin{array}{l}\text { 1. BWLT }\left(\lambda_{\max }=\right. \\
480 \mathrm{~nm})(\mathrm{n}=17)\end{array}$ & $\begin{array}{l}\text { Sleepiness: } \\
\text { ESS }\end{array}$ \\
\hline & - \% Male: 37.1 & \multirow{2}{*}{$\begin{array}{l}\text { 2. } \operatorname{ALT}\left(\lambda_{\max }=530 \mathrm{~nm}\right) \\
(\mathrm{n}=18)\end{array}$} & \multirow{2}{*}{$\begin{array}{l}\text { Sleep } \\
\text { quality: } \\
\text { PSQI }\end{array}$} \\
\hline & - Mean age: 25.9 years & & \\
\hline & - Initial GCS: N/A & \multirow{2}{*}{$\begin{array}{l}\text { (For both interventions, } \\
30 \text { minutes daily in the } \\
\text { morning) }\end{array}$} & \multirow{2}{*}{$\begin{array}{l}\text { Depression: } \\
\text { BDI-I }\end{array}$} \\
\hline & - Mean duration after TBI: 9.20 months & & \\
\hline \multicolumn{4}{|c|}{ ALT: Amber Light Therapy; NLT: No Light Therapy; BWLT: Blue-Wavelength Light Therapy. } \\
\hline \multicolumn{4}{|c|}{$\begin{array}{l}\text { TBI: Traumatic brain injury; GCS: Glasgow Coma Scale; BDI-II: Beck Depression Inventory, 2nd edition; } \\
\text { HRSD-17: 17-item Hamilton Rating Scale for Depression; FSS: Fatigue Severity Scale; ESS: Epworth } \\
\text { Sleepiness Scale; PSQI: Pittsburgh Sleep Quality Index }\end{array}$} \\
\hline
\end{tabular}

Measures used for assessing the outcomes were as follows: i) Epworth Sleepiness Scale (ESS) for sleepiness [34], ii) Pittsburgh Sleep Quality Index (PSQI) for sleep disturbance [35], iii) Beck Depression Inventory (BDI) and Hamilton Rating Scale for Depression (HRSD-17) [36, 37], and iv) Fatigue Severity Scale (FSS) for fatigue [38].

\section{Risk of bias in individual trials}

Because non-adherence to the interventions would affect the outcomes, there were some concerns regarding the deviation from the intended interventions, which resulted in some concerns on the overall risk of bias for all included studies (see Appendix 2 in Supplementary File).

\section{Results of individual trials}

Three studies reported the effectiveness of BWLT in reducing sleepiness [21, 31, 33], one study in reducing sleep disturbance [33], three studies in reducing depression [21,32,33], and three studies in reducing fatigue [21,32,33]. (see Appendix 3 in Supplementary File).

The dropouts were reported in only three nine studied groups of two RCTs [31, 33]. Because both RCTs compared the same pair of BWLT and amber light therapy, we decided to conduct a pairwise metaanalysis of these dropout rates separately as an additional analysis.

\section{Synthesis of results}

Figure $3 \mathrm{~A}$ shows the forest plot of pooled SMDs comparing the efficacy of amber light therapy and no light therapy against BWLT in reducing sleepiness. This forest plot revealed no significant difference of the comparisons. However, the overall direct comparison found that BWLT was significantly superior to amber light therapy in reducing sleepiness ( $S M D=-1.52,95 \% \mathrm{Cl}=-2.98$ to -0.07 ) (see Table 2A). 
Table 2

League table presenting the treatment estimates and 95\% confidence intervals of light therapy for behavioral symptoms and dropout rates in patients with post-traumatic brain injury ${ }^{{ }^{\dagger}}$ - a random-effect model network meta-analysis estimates (lower triangle) and direct estimates (upper triangle) ${ }^{\ddagger}$.

\begin{tabular}{|c|c|c|c|c|c|}
\hline \multicolumn{3}{|c|}{$\begin{array}{l}\text { (A) SMDs for the reduction of sleepiness (95\% } \\
\text { Cls) }\end{array}$} & \multicolumn{3}{|c|}{$\begin{array}{l}\text { (B) SMDs for the reduction of sleep } \\
\text { disturbance }(95 \% \mathrm{Cls})\end{array}$} \\
\hline BWLT & $\begin{array}{l}-0.47(-2.26 \\
\text { to } 1.31)\end{array}$ & $\begin{array}{l}-1.52(-2.98 \\
\text { to }-0.07)\end{array}$ & BWLT & $\begin{array}{l}-0.15(-1.42 \\
\text { to } 1.11)\end{array}$ & $\begin{array}{l}-0.98(-2.32 \\
\text { to } 0.37)\end{array}$ \\
\hline $\begin{array}{l}-0.80(-2.50 \\
\text { to } 0.90)\end{array}$ & NLT & $\begin{array}{l}0.57(-1.95 \text { to } \\
3.08)\end{array}$ & $\begin{array}{l}-0.40(-1.62 \\
\text { to } 0.83)\end{array}$ & ALT & $\begin{array}{l}0.20(-1.64 \text { to } \\
2.04)\end{array}$ \\
\hline $\begin{array}{l}-1.36(-2.78 \\
\text { to } 0.06)\end{array}$ & $\begin{array}{l}-0.56(-2.49 \\
\text { to } 1.38)\end{array}$ & ALT & $\begin{array}{l}-0.88(-2.18 \\
\text { to } 0.41)\end{array}$ & $\begin{array}{l}-0.49(-1.99 \\
\text { to } 1.02)\end{array}$ & NLT \\
\hline \multicolumn{3}{|c|}{$\begin{array}{l}\text { (C) SMDs for the reduction of depression ( } 95 \% \\
\text { Cls) }\end{array}$} & \multicolumn{3}{|c|}{$\begin{array}{l}\text { (D) SMDs for the reduction of Fatigue ( } 95 \% \\
\text { Cls) }\end{array}$} \\
\hline BWLT & $\begin{array}{l}-0.55(-1.09 \\
\text { to }-0.01)\end{array}$ & $\begin{array}{l}-0.77(-1.42 \\
\text { to }-0.12)\end{array}$ & BWLT & $\begin{array}{l}-1.00(-1.95 \\
\text { to }-0.06)\end{array}$ & $\begin{array}{l}-1.09(-1.76 \\
\text { to }-0.41)\end{array}$ \\
\hline $\begin{array}{l}-0.57(-1.10 \\
\text { to }-0.04)\end{array}$ & ALT & $\begin{array}{l}-0.26(-1.14 \\
\text { to } 0.62)\end{array}$ & $\begin{array}{l}-1.00(-1.86 \\
\text { to }-0.14)\end{array}$ & ALT & $\begin{array}{l}-0.09(-0.97 \\
\text { to } 0.79)\end{array}$ \\
\hline $\begin{array}{l}-0.81(-1.43 \\
\text { to }-0.20)\end{array}$ & $\begin{array}{l}-0.24(-0.94 \\
\text { to } 0.45)\end{array}$ & NLT & $\begin{array}{l}-1.09(-1.76 \\
\text { to }-0.41)\end{array}$ & $\begin{array}{l}-0.09(-0.91 \\
\text { to } 0.74)\end{array}$ & NLT \\
\hline
\end{tabular}

* SMDs less than 0 indicate the superiority of the light therapy defined in the column over the other light therapy defined in the row.

${ }^{+}$Bold figures indicate significant differences between types of light therapy.

‡ Treatment are reported in order of ranking of dropout rates. Comparison treatment should be read from left to right, and their standardized mean difference (SMD) in the cell in common between the column-defining light therapy and the row-defining light therapy.

Figure 3B shows the forest plot of pooled SMDs comparing the efficacy of amber light therapy and no light therapy against BWLT in reducing sleep disturbance. This forest plot revealed no significant difference among these comparisons. In addition, the overall direct and indirect comparisons also found no significant difference among these interventions (see Table 2B).

Figure $3 \mathrm{C}$ shows the forest plot of pooled SMDs comparing the efficacy of amber light therapy and no light therapy against BWLT in reducing depression. BWLT was significantly superior to amber light therapy ( $\mathrm{SMD}=0.57,95 \% \mathrm{Cl}=0.04$ to 1.10$)$ and no light therapy $(\mathrm{SMD}=0.81,95 \% \mathrm{Cl}=0.20$ to 1.43$)$. Both direct and indirect comparisons found that BWLT was significantly superior to both amber light therapy and no light therapy in reducing depression (all SMDs and 95\% Cls < 0.00) (see Table 2C).

Figure 3D shows the forest plot of pooled SMDs comparing the efficacy of amber light therapy and no light therapy against BWLT in reducing fatigue. BWLT was significantly superior to amber light therapy 
$(\mathrm{SMD}=1.00,95 \% \mathrm{Cl}=0.14$ to 1.86$)$ and no light therapy $(\mathrm{SMD}=1.09,95 \% \mathrm{Cl}=0.41$ to 1.76$)$. Both direct and indirect comparisons found that BWLT was significantly superior to both amber light therapy and no light therapy in reducing fatigue (all SMDs and 95\% Cls < 0.00) (see Table 2D).

All direct and indirect comparisons found no significant difference between amber light therapy and no light therapy on any outcome.

\section{Heterogeneity and inconsistency}

There was significant heterogeneity/inconsistency of sleepiness data $\left(I^{2}=87.4 \%, Q=23.87, d f=3, p<\right.$ $0.001)$, which was contributed by the heterogeneity between studies of the same design ( $Q$ within designs $=13.45, \mathrm{df}=1, \mathrm{p}<0.001$ ) and the inconsistency between studies of different designs ( $Q$ between designs $=10.41, \mathrm{df}=2, \mathrm{p}=0.006)$. The inconsistency between study designs might be a result of the three-arm design in Sinclaire's study $(Q=0.00, d f=0, p<0.001)$. The sleep-disturbance data also had the same pattern of significant heterogeneity/inconsistency.

There was no significant heterogeneity/inconsistency of depression and fatigue data $\left(I^{2}=0 \%, Q=0.47\right.$, df $=2, p=0.791 ; I^{2}=0 \%, Q=0.00, d f=1, p=0.981$, respectively).

The analysis of Separate Indirect from Direct Evidence using back-calculation method found no significant inconsistency of direct and indirect evidence for any comparison of any outcome reported in the league tables of four outcomes ( $p$ 's $>0.05$ )

\section{Additional analysis}

The dropout rates obtained from two studies were pooled on an intention-to-treat basis using a randomeffect model. The pooled relative risk $(95 \% \mathrm{Cl})$ shows no significant difference between BWLT and amber light therapy groups ( $\mathrm{RR}=3.72,95 \% \mathrm{Cl}=0.66$ to $21.34, \mathrm{I}^{2}=0 \%$ ) (see Fig. 4). We found no study comparing the dropout rates between BWLT and no light therapy.

\section{Risks of bias across studies}

The funnel plots of sleepiness, sleep disturbance, depression, fatigue, and dropout rate analyses revealed low levels of publication bias (see Appendix 4 in the Supplementary File). Because the numbers of comparison were small, we did not apply any method to calculate the bias.

\section{Discussion}

The findings of this systematic review and NMA should be viewed with caution because they were derived from only four RCTs with a small sample of 117 patients who had a history of TBI. The minimal heterogeneity, inconsistency, and imprecision of depression and fatigue data might support that BWLT was effective in mitigating post-TBI depression and fatigue. In contrast, the substantial heterogeneity, 
inconsistency, and imprecision of sleepiness and sleep disturbance data suggest that these data were not sufficient to support the efficacy of BWLT for post-TBI sleepiness and sleep disturbance.

To our knowledge, this is the first quantitative synthesis of BWLT for post-TBI sleepiness, sleep disturbance, depression, and fatigue. The efficacy of BWLT for post-TBI depression and fatigue found in this systematic review was in line with the results of three individual studies [21,32,33]. Its efficacy for depression and fatigue has also been reported in other medical and psychiatric conditions. For example, a recent review suggested that bright light therapy was effective for seasonal and non-seasonal depression and depression in dementia [39]. In addition, another systematic review also found that bright light therapy combined with psychosocial therapies was ranked the best in reducing cancer-related fatigue [40]. Taken together, the present and previous findings suggest that bright light therapy, especially the BWLT, is effective in mitigating depressive and fatigue symptoms across the medical and psychiatric conditions, including the sequelae of TBI.

This systematic review found inconclusive efficacy of BWLT for post-TBI sleepiness. Similar findings have ever reported in patients with Parkinson's disease [41]. However, the post-hoc analysis of this RCT still found the benefit of bright light therapy for sleepiness in a subgroup of patients with more severe sleepiness (ESS score > 11). Future trials in patients with moderate to severe sleepiness may be helpful to determine the therapeutic effects of BWLT for this post-TBI sleep problems.

Although Quara Salve's study found that BWLT might improve sleep quality, the findings of our NMA and two included studies did not support this benefit [21,33]. Previous systematic reviews also reported inconclusive results regarding the use of BWLT for sleep disturbance. While a review found the efficacy of BWLT for sleep problems in general, circadian rhythm sleep disorders, insomnia, and sleep problems related to Alzheimer's disease/dementia [42], the other study did not find such benefits in nursing home residents with sleep problems [43].

The data obtained from Sinclair's study might be a cause of substantial heterogeneity and inconsistency of sleepiness and sleep disturbance data. The participants of this study appeared to be different from others in at least three respects. The participants in this study had a high prevalence rate of fatigue ( $95 \%$ vs. sleep problems in other studies), the highest proportion of male participants ( $83.3 \%$ vs. $37 \%-55 \%$ in other studies), and more advanced age (mean of 42 years vs. 23-37 years in other studies). It remains unclear if these factors contributed to the heterogeneity of data or were the effect modifiers of BWLT benefits on sleepiness and sleep disturbance.

The mechanisms of action of BWLT in reducing post-TBI depression and fatigue remain unknown. However, a recent study in healthy young adults found that melatonin secretion was greater declined after the morning exposure to blue-enriched white light in comparison to warm white light [44]. Those physiological findings were in line with the behavioral findings that blue-enriched white light also decreased the participants' sleepiness and depressed mood to a greater extent. More evidence on the complex interactions among light, melatonin, mood, and sleep may help us understand more about the 
mechanisms of action of BWLT on mood and behavior not only in post-TBI but also in other mental and physical disorders.

Although this NMA found the benefits of BWLT in reducing depression and fatigue, these results still should be applied with caution. Based on the Grading of Recommendation Assessment, Development and Evaluation (GRADE) approach, the randomized controlled trials included in the NMAs were high quality of evidence.[45] Among the five domains included in the GRADE approach, there was no concern on the inconsistency, indirectness, and imprecision of the NMA estimates for depression and fatigue. However, due to the risks of bias and the inability to exclude publication bias among included studies, the current evidence remains insufficient to support the clinical application of BWLT for post-TBI depression and fatigue. In addition, health care providers should also be aware of some common adverse events of BWLT, including nausea, diarrhea, headache, and eye irritation [12].

\section{Limitations}

There were some limitations of this systematic review. First, this review included only a small number of trials and participants ( $\mathrm{N}=117$ and $4 \mathrm{RCTs}$ ). For some outcomes, e.g., fatigue, dropout rates, the analyses included only 50 or 67 participants of two RCTs. A type II error, therefore, cannot be excluded in interpreting the inconclusive results regarding the benefits of BWLT on sleepiness and sleep disturbance. Second, the study durations on the included trials were relatively short (4-6 weeks) in comparison to the chronic nature of post-TBI depression, fatigue, sleepiness, and sleep disturbance. Future studies should have a longer study duration and include the assessment of symptoms several months after the end of treatment. Finally, the changed scores of many outcomes in the trials included in this review were not available. The requests for these data were unsuccessful. Although we tried to apply some methods to calculate the missing SDs, these might be less accurate than the actual ones.

\section{Conclusions}

BWLT may be effective for post-TBI depression and fatigue. The current evidence remains insufficient to support the clinical application of BWLT for post-TBI depression and fatigue. Future studies in larger sample sizes with longer study duration are warranted.

\section{Abbreviations}

BDI

Beck Depression Inventory

BWLT

Blue-wavelength light therapy

Cl

Confidence interval

ESS 
Epworth Sleepiness Scale

FSS

Fatigue Severity Scale

HRSD

Hamiltion Rating Scale for Depression

NMA

Network meta-analysis

PSQI

Pittsburgh Sleep Quality Index

RCT

randomized controlled trial

RoB

Risk of bias

RR

Relative risk

SD

Standard deviation

SMD

Standardized mean different

TBI

Post-traumatic brain injury

\section{Declarations}

Ethics approval and consent to participate

Not applicable.

Consent for publication

Not applicable.

\section{Availability of data and materials}

The datasets used and/or analyzed during the current study are available from the corresponding author on reasonable request.

\section{Competing interests}

The authors declare that they have no competing interests.

\section{Funding}


This work was supported by a grant from Chiang Mai University, Chiang Mai, Thailand (grant no. 16/2563 for M.S.). The sponsor had no role in the analysis and interpretation of data, the manuscript preparation or writing, or the decision to submit the manuscript.

\section{Authors' contributions}

All authors developed the systematic review protocol. KS performed the literature search and removed duplicated records. KS and YS screened and selected the studies according to the inclusion criteria. KS and PS extracted trial and outcome data from the trials. KS and MS performed the analyses and drafted the manuscript. All authors interpreted data and approved the final manuscript.

\section{Acknowledgements}

We wish to thank Joan Peagam for her assistance with manuscript editing.

\section{References}

1. GBD 2016 Traumatic Brain Injury and Spinal Cord Injury Collaborators. Global, regional, and national burden of traumatic brain injury and spinal cord injury, 1990-2016: a systematic analysis for the Global Burden of Disease Study 2016. Lancet Neurol. 2019;18:56-87.

2. Dewan MC, Rattani A, Gupta S, Baticulon RE, Hung Y-C, Punchak M, et al. Estimating the global incidence of traumatic brain injury. J Neurosurg. 2018;130:1-18.

3. Ponsford JL, Ziino C, Parcell DL, Shekleton JA, Roper M, Redman JR, et al. Fatigue and sleep disturbance following traumatic brain injury-their nature, causes, and potential treatments. $J$ Head Trauma Rehabil. 2012;27:224-33.

4. Imbach LL, Büchele F, Valko PO, Li T, Maric A, Stover JF, et al. Sleep-wake disorders persist 18 months after traumatic brain injury but remain underrecognized. Neurology. 2016;86:1945-9.

5. Scholten AC, Haagsma JA, Cnossen MC, Olff M, van Beeck EF, Polinder S. Prevalence of and Risk Factors for Anxiety and Depressive Disorders after Traumatic Brain Injury: A Systematic Review. J Neurotrauma. 2016;33:1969-94.

6. Cantor JB, Ashman T, Gordon W, Ginsberg A, Engmann C, Egan M, et al. Fatigue after traumatic brain injury and its impact on participation and quality of life. J Head Trauma Rehabil. 2008;23:41-51.

7. Mathias JL, Alvaro PK. Prevalence of sleep disturbances, disorders, and problems following traumatic brain injury: a meta-analysis. Sleep Med. 2012;13:898-905.

8. Jorge RE, Arciniegas DB. Mood disorders after TBI. Psychiatr Clin North Am. 2014;37:13-29. 
9. Ferentinos P, Kontaxakis V, Havaki-Kontaxaki B, Paparrigopoulos T, Dikeos D, Ktonas P, et al. Sleep disturbances in relation to fatigue in major depression. J Psychosom Res. 2009;66:37-42.

10. Melrose S. Seasonal Affective Disorder: An Overview of Assessment and Treatment Approaches. Depress Res Treat. 2015;2015:178564.

11. Mårtensson B, Pettersson A, Berglund L, Ekselius L. Bright white light therapy in depression: A critical review of the evidence. J Affect Disord. 2015;182:1-7.

12. Maruani J, Geoffroy PA. Bright Light as a Personalized Precision Treatment of Mood Disorders. Front Psychiatry. 2019;10:85.

13. Cajochen C, Zeitzer JM, Czeisler CA, Dijk DJ. Dose-response relationship for light intensity and ocular and electroencephalographic correlates of human alertness. Behav Brain Res. 2000;115:75-83.

14. Rüger M, Gordijn MCM, Beersma DGM, de Vries B, Daan S. Weak relationships between suppression of melatonin and suppression of sleepiness/fatigue in response to light exposure. J Sleep Res. 2005;14:221-7.

15. Chellappa SL, Steiner R, Blattner P, Oelhafen P, Götz T, Cajochen C. Non-visual effects of light on melatonin, alertness and cognitive performance: can blue-enriched light keep us alert? PloS One. 2011;6:e16429.

16. Kozaki T, Kubokawa A, Taketomi R, Hatae K. Light-induced melatonin suppression at night after exposure to different wavelength composition of morning light. Neurosci Lett. 2016;616:1-4.

17. Center for Environmental Therapeutics. Light Box Selection Criteria. 2017. https://cet.org/light-boxselection-criteria/. Accessed 2 Aug 2020.

18. Viola-Saltzman M, Musleh C. Traumatic brain injury-induced sleep disorders. Neuropsychiatr Dis Treat. 2016;12:339-48.

19. Juengst SB, Kumar RG, Wagner AK. A narrative literature review of depression following traumatic brain injury: prevalence, impact, and management challenges. Psychol Res Behav Manag. 2017;10:17586.

20. Xu G-Z, Li Y-F, Wang M-D, Cao D-Y. Complementary and alternative interventions for fatigue management after traumatic brain injury: a systematic review. Ther Adv Neurol Disord. 2017;10:229-39.

21. Sinclair KL, Ponsford JL, Taffe J, Lockley SW, Rajaratnam SMW. Randomized controlled trial of light therapy for fatigue following traumatic brain injury. Neurorehabil Neural Repair. 2014;28:303-13.

22. Hutton B, Salanti G, Caldwell DM, Chaimani A, Schmid CH, Cameron C, et al. The PRISMA extension statement for reporting of systematic reviews incorporating network meta-analyses of health care 
interventions: checklist and explanations. Ann Intern Med. 2015;162:777-84.

23. Higgins J, Green S. Cochrane Handbook for Systematic Reviews of Interventions Version 5.1.0 [Updated March 2011]. The Cochrane Collaboration; 2011. www.handbook.cochrane.org.

24. Higgins J, Thomas J, Chandler J, Cumpston M, Li T, Page M, et al. Cochrane Handbook for Systematic Reviews of Interventions. 2nd Edition. Chichester (UK): John Wiley \& Sons; 2019.

25. Higgins JPT, Thompson SG, Deeks JJ, Altman DG. Measuring inconsistency in meta-analyses. BMJ. 2003;327:557-60.

26. Rücker G, Krahn U, König J, Efthimiou O, Schwarzer G. netmeta: Network Meta-Analysis using Frequentist Methods. 2020. https://CRAN.R-project.org/package=netmeta.

27. McGuinness LA, Higgins JPT. Risk-of-bias VISualization (robvis): An R package and Shiny web app for visualizing risk-of-bias assessments. Res Synth Methods. 2020.

28. Balduzzi S, Rücker G, Schwarzer G. How to perform a meta-analysis with R: a practical tutorial. Evid Based Ment Health. 2019;22:153-60.

29. R Core Team. A language and environment for statistical computing. R Foundation for Statistical Computing. Vienna, Austria; 2020. https://www.R-project.org/.

30. RStudio Team. RStudio: Integrated Development Environment for R. Boston, MA: RStudio, Inc.; 2019. http://www.rstudio.com/.

31. Killgore WDS, Vanuk JR, Shane BR, Weber M, Bajaj S. A randomized, double-blind, placebo-controlled trial of blue wavelength light exposure on sleep and recovery of brain structure, function, and cognition following mild traumatic brain injury. Neurobiol Dis. 2020;134:104679.

32. Quera Salva M-A, Azabou E, Hartley S, Sauvagnac R, Leotard A, Vaugier I, et al. Blue-Enriched White Light Therapy Reduces Fatigue in Survivors of Severe Traumatic Brain Injury: A Randomized Controlled Trial. J Head Trauma Rehabil. 2020;35:E78-85.

33. Raikes AC, Dailey NS, Shane BR, Forbeck B, Alkozei A, Killgore WDS. Daily Morning Blue Light Therapy Improves Daytime Sleepiness, Sleep Quality, and Quality of Life Following a Mild Traumatic Brain Injury. J Head Trauma Rehabil. 2020.

34. Johns MW. Sleepiness in different situations measured by the Epworth Sleepiness Scale. Sleep. 1994;17:703-10.

35. Buysse DJ, Reynolds CF, Monk TH, Berman SR, Kupfer DJ. The Pittsburgh Sleep Quality Index: a new instrument for psychiatric practice and research. Psychiatry Res. 1989;28:193-213. 
36. Beck, A.T., Steer, R.A., Brown, G.K. Manual for the Beck Depression Inventory-II. San Antonio, TX: Psychological Corporation; 1996.

37. Hamilton M. A rating scale for depression. J Neurol Neurosurg Psychiatry. 1960;23:56-62.

38. Krupp LB, LaRocca NG, Muir-Nash J, Steinberg AD. The fatigue severity scale. Application to patients with multiple sclerosis and systemic lupus erythematosus. Arch Neurol. 1989;46:1121-3.

39. Mitolo M, Tonon C, La Morgia C, Testa C, Carelli V, Lodi R. Effects of Light Treatment on Sleep, Cognition, Mood, and Behavior in Alzheimer's Disease: A Systematic Review. Dement Geriatr Cogn Disord. 2018;46:371-84.

40. Wu C, Zheng Y, Duan Y, Lai X, Cui S, Xu N, et al. Nonpharmacological Interventions for Cancer-Related Fatigue: A Systematic Review and Bayesian Network Meta-Analysis. Worldviews Evid Based Nurs. 2019;16:102-10.

41. Raymackers J-M, Andrade M, Baey E, Vanneste M, Evrard F. Bright light therapy with a head-mounted device for anxiety, depression, sleepiness and fatigue in patients with Parkinson's disease. Acta Neurol Belg. 2019;119:607-13.

42. van Maanen A, Meijer AM, van der Heijden KB, Oort FJ. The effects of light therapy on sleep problems: A systematic review and meta-analysis. Sleep Med Rev. 2016;29:52-62.

43. Shang B, Yin H, Jia Y, Zhao J, Meng X, Chen L, et al. Nonpharmacological interventions to improve sleep in nursing home residents: A systematic review. Geriatr Nur (Lond). 2019;40:405-16.

44. Choi K, Shin C, Kim T, Chung HJ, Suk H-J. Awakening effects of blue-enriched morning light exposure on university students' physiological and subjective responses. Sci Rep. 2019;9:345.

45. Puhan MA, Schünemann HJ, Murad MH, Li T, Brignardello-Petersen R, Singh JA, et al. A GRADE Working Group approach for rating the quality of treatment effect estimates from network meta-analysis. BMJ. 2014;349:g5630.

\section{Figures}




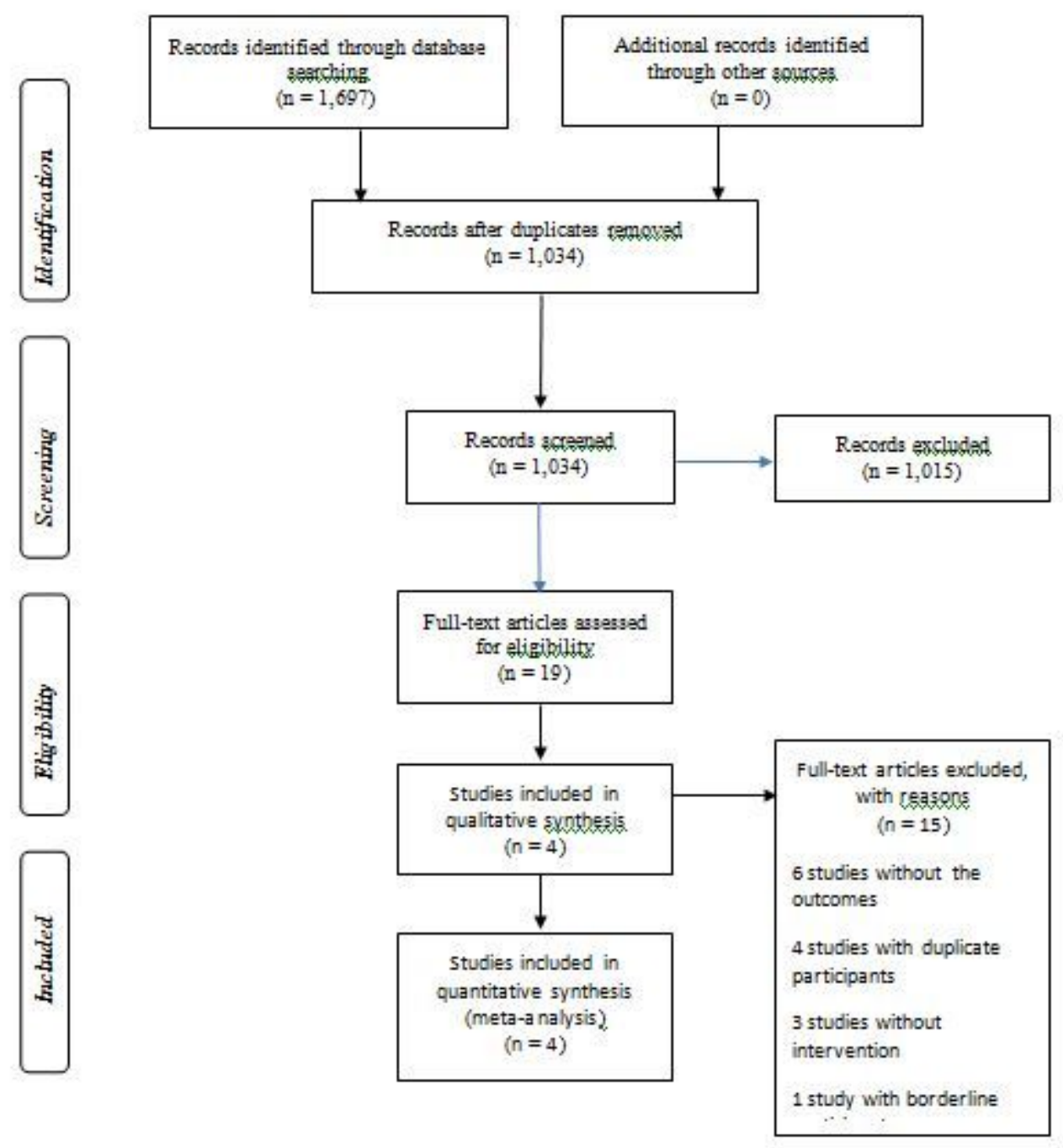

Figure 1

PRISMA flow diagram of literature search and study selection.

(A)

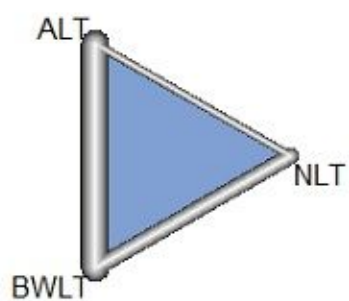

BWLT

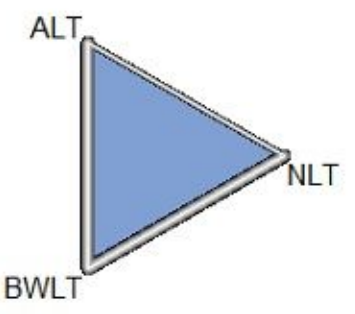

BWLT

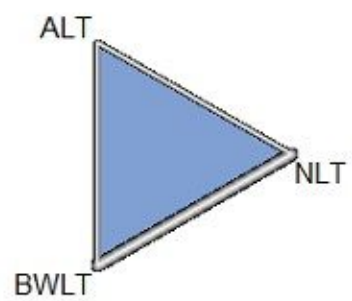

BWLT

\footnotetext{
ALT: Amber Light Therapy; NLT: No Light Therapy; BWLT: Blue-Wavelength Light Therapy.
} 
Figure 2

Network meta-analysis plots of light therapy for behavioral symptoms of post-traumatic brain injury (A) sleepiness ( 3 treatments among 6 pairwise comparisons in 4 RCTs); (B) sleep disturbance and depression (3 treatments among 5 pairwise comparisons in 3 RCTs); (C) fatigue (3 treatments among 4 pairwise comparisons in 2 RCTs). The nodes in the graph layout correspond to the types of light therapy, and edges display the observed treatment comparisons. The thickness of edge indicates the number of comparisons.

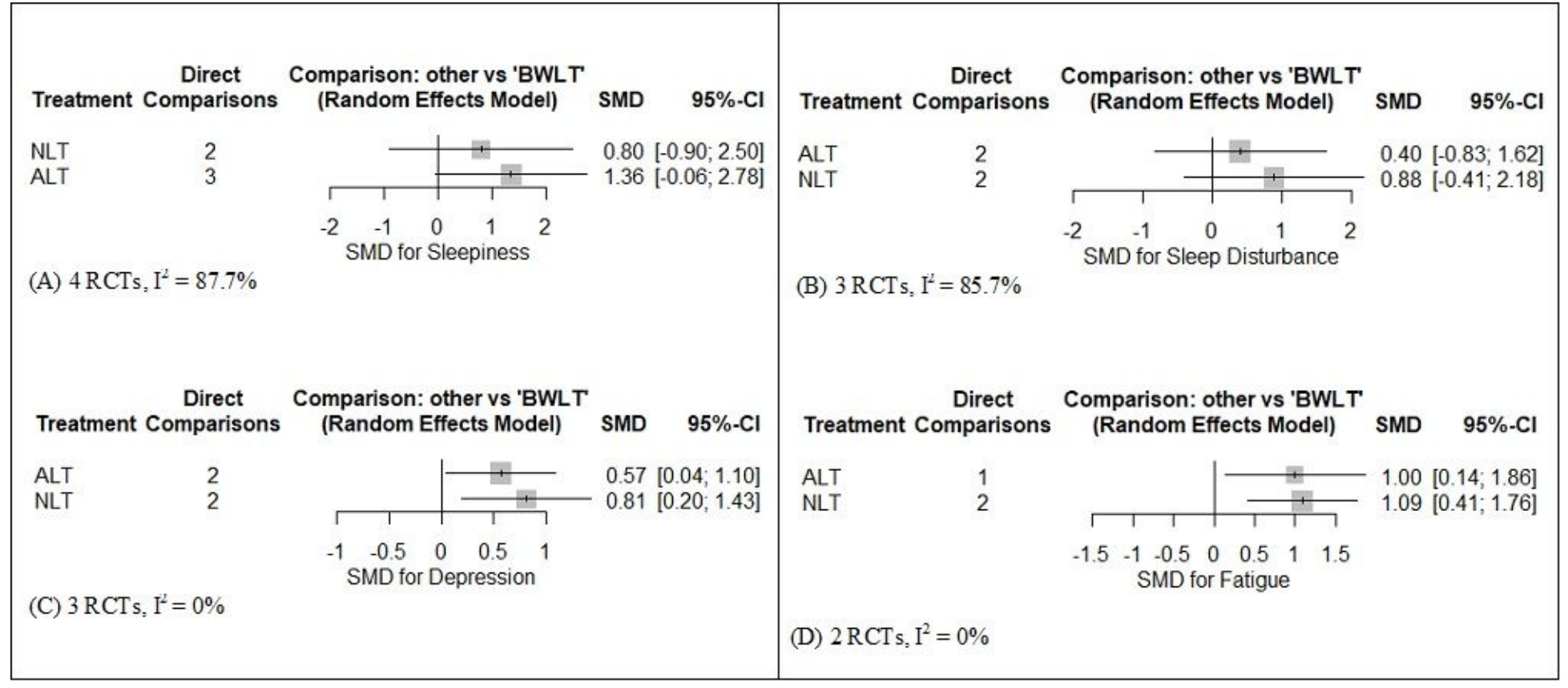

\section{Figure 3}

Forest plots for the efficacy of ALT and NLT for behavioral symptoms of post-traumatic brain injury compared to BWLT: (A) SMDs for the reduction of sleepiness ; (B) SMDs for the reduction of sleep disturbance; (C) SMDs for the reduction of depression; and (D) SMDs the reduction of fatigue. SMDs $<1$ indicate the superiority of BWLT against ALT and NLT. ALT: Amber Light Therapy; NLT: No Light Therapy; BWLT: Blue-Wavelength Light Therapy.

\begin{tabular}{|c|c|c|c|c|}
\hline Study & \multicolumn{4}{|c|}{$\begin{array}{l}\text { Experimental Control } \\
\text { Events Total Events Total }\end{array}$} \\
\hline Killgore 2020 & 2 & 16 & 0 & 6 \\
\hline Raikes 2020 & 3 & 17 & 1 & \\
\hline $\begin{array}{l}\text { Fixed effect model } \\
\text { Random effects model }\end{array}$ & & 33 & & \\
\hline
\end{tabular}

Risk Ratio

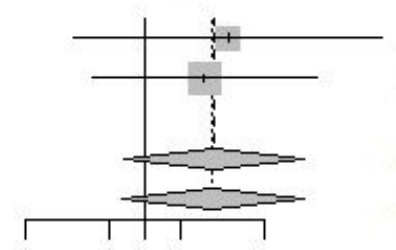

$0.1 \quad 0.512 \quad 10$

Favors BWLT Favors ALT
Weight Weight RR $\quad 95 \%-\mathrm{Cl}$ (fixed) (random) $5.00[0.26 ; 96.36] \quad 34.0 \% \quad 34.8 \%$ $3.18[0.36 ; 27.65] \quad 66.0 \% \quad 65.2 \%$

$\begin{array}{lrr}3.80[0.66 ; 21.71] & 100.0 \% & -- \\ 3.72[0.65 ; 21.34] & -- & 100.0 \%\end{array}$

Heterogeneity: $I^{2}=0 \%, \tau^{2}=0, p=0.81$ 
Figure 4

Forest plots for the dropout rates of BWLT compared with ALT in patients with a history of traumatic brain injury. ALT: Amber Light Therapy; NLT: No Light Therapy; BWLT: Blue-Wavelength Light Therapy.

\section{Supplementary Files}

This is a list of supplementary files associated with this preprint. Click to download.

- PRISMANMAchecklistJNERv1.0.docx

- SupplementaryFileJNER.docx 